\title{
Developing climate change communication strategies with game theory
}

\author{
Andrew Larkin \\ College of Public Health and Human Sciences, Oregon State University, Corvallis, Oregon, USA.
}

Accepted 24 January, 2019

\begin{abstract}
Climate change perceptions and perceived risk in the United States has become increasingly partisan, with increased belief in and support for climate change and regulation among democrats, but decreased belief and support among republicans. These divergences are partly attributable to increasingly partisan news outlet viewership and coverage. We developed a game theory model to identify optimal climate change communication strategies through news media outlets. Actor strategies included whether to communicate with pro- and/or anti-climate change new outlets, and to emphasize regulation, renewable energy, whether climate change is real, man-made, and/or causes harm to the United States Payoffs consisted of change in public opinion for each of the candidate topics actors can chose to emphasize. Twenty-five sequential games were played independently for each of the 50 states within the United States. In all 25 repeated games and for all 50 states, strategies with the greatest output for pro and anti-climate change actors consistently reinforced partisan perceptions, driving democrats towards and republicans away from supporting climate change regulation. Predicted bipartisanship support was greatest for renewable energy but varied widely by state.
\end{abstract}

Keywords: Climate change, game theory, communication, partisan.

Email: Andrew.larkin@oregonstate.edu.

\section{INTRODUCTION}

Climate change is recognized across the globe as a universal problem. While support for climate change mitigation has steadily gained traction internationally, support from and within the United States has been intermittent. On April 22, 2016, U.S. Secretary of State John Kerry signed the Paris Climate Agreement on behalf of the United States. However, just 16 months later, on August $4^{\text {th }}$ 2017, U.S. President Donald Trump notified the United Nations that the United States intended to withdraw.

The abrupt policy shift from the United States in such a short time reflects the sharp political divide in climate change belief and perceived risk among both US lawmakers and the general population. Eighty-four percent of self-identified democrats, including Barack Obama who was president when John Kerry signed the Paris Agreement, are worried about global warming, in contrast to $44 \%$ of self-identified republicans, including
Donald Trump (Carmichael et al., 2017). Effective and sustained climate change regulation across multiple presidential administrations is unlikely given the current differences in climate change perceptions. Climate change experts and regulation proponents therefore need to engage in effective bipartisan climate change communication. To develop optimal strategies, experts need to know the spatial and temporal trends and hypothesized pathways of influencing climate change perceptions among the general public.

\section{Temporal trends in public opinion}

In $199966 \%$ of Republicans and $67 \%$ of Democrats were worried about global warming. In the same Gallup poll taken in 2016, 44\% of Republicans and $84 \%$ of Democrats were worried about global warming 
(Carmichael et al., 2017). While international concern about climate change has steadily increased in both developing and developed countries (Lee et al., 2015), the concern among the American general public remained stagnant overall yet sharply divided between political parties. This sharp divergence between political groups suggests actors with strong associations to politically-related demographics are largely responsible for changes over the past 20 years in climate change perceptions, and has significant potential to provide insights into strategies and optimal payoffs for climate scientists who want to reduce the gap between public and expert perceptions.

\section{Geographical and demographic distribution of public opinion}

Belief that climate change is happening significantly differs by geographical region. States with the lowest mean belief in climate change included West Virginia $(54 \%)$ and Wyoming (55\%), while regions with the highest aggregated beliefs in climate change included Hawaii $(77 \%)$ and the District of Colombia (81\%) (Howe et al., 2015). In 2015, Howe and associates found that census block level estimates of gender, race, education, political affiliation, and a random effect for geographical location predicted mean climate change belief at the census block level within the survey sampling error. In a follow up study, Mildenberger et al. (2017) derived similar results using linear regression models with demographic predictor variables similar to those utilized by Howe. While insufficient to distinguish causation from correlation, these data clearly demonstrate that climate change perceptions are strongly associated with socio economic status, geography, and demographic characteristics that are also strongly associated with party affiliation.

\section{Hypothesized mechanisms of and factors which influence public opinion about climate change}

Mechanisms which influence public opinion about climate change can be grouped into the following five categories, modified and expanded from those originally proposed by Carmiccahel et al. (2017): (1) media coverage, including social media, (2) extreme local and distal weather events, (3) scientific reports and communications, (4) competing concerns and priorities, and (5) political and ideological leaders.

\section{Media Coverage}

Regardless of current opinion, media coverage tends to reinforce currently held beliefs among members of the general population. Republicans and Democrats alike preferentially consume content which aligns with (called an echo chamber or friendly media) and dismiss media that challenges (called a boomerang effect or hostile media) their current opinions, respectively. Echo chambers tend to reinforce currently held beliefs and increase viewer resiliency toward alternative views. Boomerang effects similarly increase viewer skepticism of media sources that conflict with currently held beliefs. With more than $1 / 3$ of young adults acquiring news exclusively from social media (Chan-Olmsted et al., 2013; Perrin, 2015), media coverage has now spread to interactive digital content, where participants can reinforce (either through support or trolling) or challenge (through meaningful discussion or trolling) group opinions (Shin et al., 2014). There are several overlapping hypotheses for increasingly partisan climate change media preference, including reduced credibility towards discordant news sources (Metzger et al., 2015), cognitive dissonance (discomfort that arises when personal beliefs are called into question), and invested interest in related topics, such as local economy associations with the fossil fuel industry.

\section{Extreme local and distal weather events}

Extreme weather events can constitute either local extremes in weather conditions, such as extreme magnitudes or durations of high and low temperatures, or major disaster events that may change in frequency and severity due to climate change, including hurricanes, droughts, and severe heat waves both international (Lee et al., 2015) and national (US) (Carmichael et al., 2017) studies found mixed results with respect to local and distal weather events. Impacts of distal events in particular are difficult to determine because of their dependence on news media for increased awareness (Carmichael et al., 2017). Up to present studies have largely focused on impacts of isolated acute seasonal events rather than cumulative impacts of multiple events, in large part due to a paucity of multi-decadal time series data sets.

\section{Scientific reports}

Scientific research studies and formal reports, such as through the World Health Organization and International Panel on Climate Change, can increase climate change literacy and draw attention towards potential consequences of climate change. Studies investigating impacts of scientific reports on public climate change opinion have been mixed, with receptiveness to reports based in part on political affiliation (Democratic opinions are more responsive) and perceived scientific credibility (Conservatives view climate change scientists as less 
credible, perhaps in part because of conservative media coverage) (Bliuc et al., 2015). Impacts of scientific reports also appear to be related to media source, with television and popular science magazines generating greater awareness than research reports and publications (Carmichael et al., 2017). While the best course of strategy is unclear, there is a growing consensus among the scientific community that communication strategies focused on improving scientific literacy alone are insufficient (Hicks, 2017).

\section{Competing resources, priorities and international policies}

Environmental health (e.g. air and water quality) and industrial development are often competing interests for public opinion (Hicks, 2017; Shapiro, 2016). Climate change perceptions may therefore be dependent on competing interest from competing interests that might be negatively impacted by climate change regulation, including local jobs and community cohesion (Hicks, 2017). Similarly, competing risks such as warfare, unemployment, and political scandals can reduce perceived importance of climate change among democrat and republican members of the public. International policies on climate change can also influence change, with greater support for national climate change regulation with rather than without identical policies enforced at an international scale (i.e. if we regulate our emissions, everyone should be forced to regulate emissions) (Tingley and Tomz, 2014). This is in agreement with early game theory models at a global scale which found cooperative models yielded greater payoffs than non-cooperative models (although high emission countries such as the US has the smallest payoffs (Nordhaus and Yang, 1996)).

\section{Political and ideological leaders}

As described previously, opinions about climate change since the 1990's have become increasingly partisan. While some of the partisan divide can be attributed to new media preferences, several studies suggest political and ideological leaders have also reinforced the political divide (Shapiro, 2016). The republican congress in general grew increasingly critical of climate change in the early 2000's as republican senators favoring climate change were voted out of office in favor of climate change critics (Carmichael et al., 2017). Like extreme weather events, political leader impacts on climate change is dependent in part on media coverage, and consequently it can be difficult to estimate their respective independent impacts on climate change opinions.

Media coverage can interact with all the factors mentioned above, making news media outlets an essential component to climate change communication. However, actors can choose or "strategize" what message they focus on, and which outlets they cooperate with. Regardless of whether an actor cooperates with media outlets, it is difficult to envision a significant widespread impact on climate change perceptions that does not involve news media coverage. We developed models for each state to evaluate and predict how actor interactions with news media outlets and other competitive actors influence climate change opinions among the general public.

\section{METHODS}

\section{Game theory model}

Game theory models are designed to capture interactions between rational actors where the potential actions of actor A will influence actions chosen by actor B. Actors, which can consist of groups or individuals, are considered rational if they make decisions which maximize their expected output given the available information.

In this game theoretic model, proponents and opponents of climate change compete for public opinion of several highly correlated climate change topics. The game framework consists of the following:

1) There are two actors in the game. Actor 1 is the collective group of proponents for climate change regulation, including academics, politicians, and nature conservancy groups. Actor 2 consists of opponents of climate change regulation, including politicians, lobbyists and businesses against climate change regulation.

2) The primary goal for Actor 1 is to achieve sustained agreement that climate change is real, impacted by humans, and support for renewable energies and climate change regulation. In contrast, the primary goal for Actor 2 is to convince the public that climate change in not happening, not related to human activity, and to block support for climate change regulation and renewable energies.

3) The game model is competitive. In a competitive model, actors have opposing goals. In this game model, a positive change in public opinion for actor 1 corresponds to an equally negative change in public opinion for actor 2 (zero sum model). The game model is also simultaneous, where Actors 1 and 2 make their decisions and concomitant actions simultaneously rather than in turn. In simultaneous models, actors can predict but do not know for certain which actions their opponents will make.

4) Actors in this game have complete symmetric information about opponent moves and current state of the environment. In other words, both actors are fully 
aware of the current state of public opinion and the expected change in public opinion for all combinations of actor 1 -actor 2 actions.

5) Games are repeatedly played, with payoffs from game $i$ contributing to payoffs from game $i+1$. In other words, changes in public opinion are cumulative, and level of public opinion at the start of each game is based on public opinion levels at the end of the previous game.

6) Actors have four options for communicating with news media outlets

a. Cooperate with a news outlet that favors climate change regulation

b. Cooperate with a news outlet that opposes climate change regulation

c. Cooperate with multiple news outlets for and against climate change regulation

d. Do not cooperate with any news outlets.

7) Additionally, actors have up to 5 topics they can focus on while engaging with news outlets. Actors can choose to discuss a combination of topics (i.e. mixed strategy), and chose separate topics for pro- and anticlimate change news outlets.

a. Whether climate change should be regulated (e.g. tax carbon emissions)

b. Whether to support renewable energy funding

c. Whether climate change is happening

d. Whether humans are responsible for climate change

e. Whether climate change is harmful to the US

\section{Utility functions and parameters}

Utility functions are the algebraic expressions describing how actor actions change model output. The payoff consists of the change(s) in the system state which directly influence decisions of participants in the game, relative to the desired output for each actor. For example, increased public support for climate change regulation is a positive payoff for a proponent of regulation and negative payoff for an opponent of regulation. Payoff for both actors is the sum change in public opinion of the five discussion topics in 7). Positive and negative payoffs for actor 1 correspond to increased and decreased support, respectively, for climate change regulation. Opinion scores range from -1 to 1 , where -1 corresponds to completely opposed to the conversation topic (e.g. climate change regulation, renewable energy), +1 corresponds to completely in favor of the topic, and 0 corresponds to no opinion. Utility functions for actors 1 and 2 are identical, except for the direction of the coefficient. The utility function for actor 1 is derived below, and the utility function for actor 2 is the utility function for actor 1 multiplied by -1 .

The utility function for actor 1 is:
$I_{\text {Actor }_{1}}=\sum_{i=1}^{3} W_{i} \Delta$ Opinion $_{\text {Groupi }}-1<I_{\text {Actor }}<1$

Where $i$ is the political group with $\Delta$ Opinion $_{\text {Groupi }}$ and $\mathrm{Wi}$ is the fraction of the population of interest in group i. Changes in opinion need to be calculated separately and then summed for democratic, republican, and independent groups as several parameters for the remaining equations such as current level of support for climate change regulation differs between political groups.

The change in opinion for group I after hearing a news story that included participation from actor 1 is the product of the strength of the currently held group opinion ( $\left.I_{\text {Resilliance }}\right)$, the relative difference between group and actor opinion $\left(I_{\text {Agree }}\right)$, and the perceived reputation of the news media outlet(s) presenting the news story ( $\left.\mathrm{I}_{\text {Media }}\right)$ (Equation 2).

$\Delta$ Opinion $_{\text {Group } i}=I_{\text {Resiliance } i} * I_{\text {Agree } i} * \sum_{j=1}^{2} I_{\text {Media } j i}$

While the calculated

I Resiliance follows a symmetric negative exponential distribution, ranging from 0 to 1 (Equation 3, Figure 1B). Groups with strongly held beliefs (approaching +1 or -1 ) are unlikely to significantly change their opinion, whereas groups with no previously help beliefs (opinion score of 0 ) are highly receptive to climate change messages.

$I_{\text {Resiliance } i}=e^{-\mid \text {opinion }_{\text {Group } i} \mid} 0<I_{\text {Resiliance } i}<1$

$I_{\text {Agree }}$ follows a negative exponential distribution and ranges from 0 to 1 (Equation 4, Figure 1C). Groups with opinion scores closer to the actor opinion $\left(I_{\text {Agree }}\right.$ approaches 1) are more receptive to actor communications than groups where the actor and group opinion scores significantly differ $\left(\mathrm{I}_{\text {Agree }}\right.$ approaches 0$)$.

$I_{\text {Agree }}=e^{\left.- \text {(opinion }_{\text {Actor-Opinion }} \text { Group } i\right)}, 0 \leq I_{\text {Agree }} \leq 1$

$I_{\text {Media }}$ follows a conditional distribution, dependent on whether the group's political party supports or opposes the actors message and ranges from -1 to 1 (Equation 5, Figure 1A). Messages supported by the group's political party will always have a zero or positive impact of group opinions regardless of media source reputation, while the impact of messages that are opposed by the group's political party will depend on the reputation of the news outlet. If an actor's position is opposed by the political party and the actor participates with a news outlet with a negative reputation, then the group's opinion further diverges from the actor's position (i.e. boomerang effect, $I_{\text {Media }}$ is negative). If an actor's position is supported by the political party and the actor participates with a news outlet with a negative reputation, then the group will view the news outlet as biased and hostile towards the actor and the group's opinion will move towards the actor (i.e. 


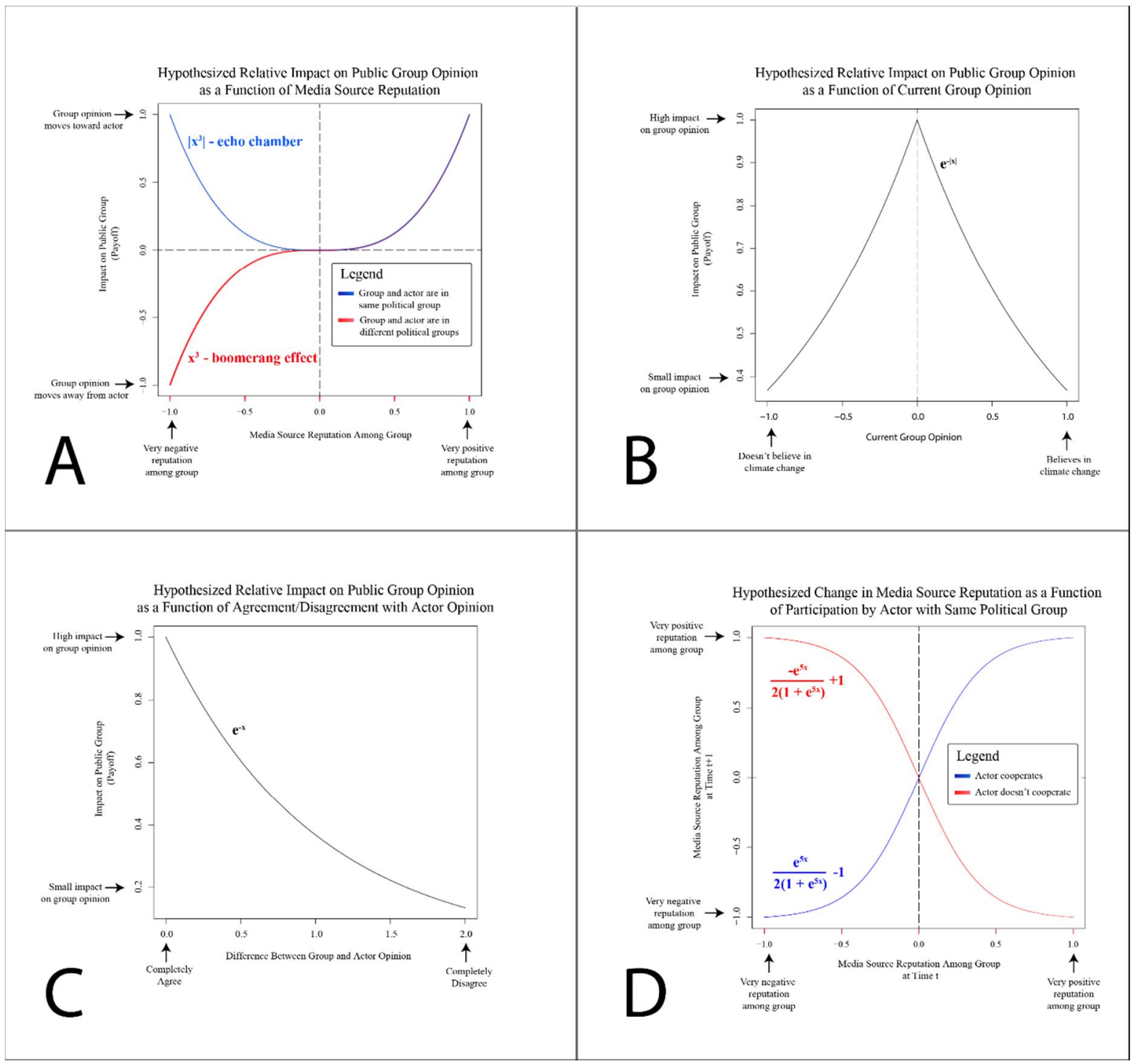

Figure 1. Relative impacts of model properties on actor utility functions and game state. Clockwise from top left: relative impacts of A) news outlets, conditional on if actor messages are supported by the political party, B) current group resolve, C) divergence between group and actor opinion, and D) if an actor participates with a sympathetic news outlet and reinforces the echo chamber effect.

echo chamber, $I_{\text {Media }}$ is positive).

$I_{\text {Media } j i}=\left\{\begin{array}{c}\text { Reputation }_{\text {Media } j i}{ }^{3}, \text { group } i \text { and actor differ in political group } \\ \text { IReputation } \\ \text { Media } j i\end{array}\right.$

\section{Change in news outlet reputation over multiple games}

The echo chamber effect (Figure $1 \mathrm{~A}$ ) requires continued reinforcement from actors and the invested political party (Equation 6, Figure 1D). If an actor's position is supported by a group's political party and an actor participates in a news outlet, then the reputation of the news outlet will increase over time. Conversely, if a news outlet does not include actors' representative of a political party position, then the news outlet reputation among members of the unrepresented political party will decrease over time. Because the derived model is a repeated game, after each game the reputation of each media outlet is updated based on if each actor participates in (i.e. cooperates with) news outlet stories. 
Reputation $_{\text {Mediajit }+1}=\left\{\begin{array}{c}2 \sqrt{\frac{\text { Reputation }_{\text {Mediajit }}+1}{2}}-1, \text { actor participates } \\ -2 \sqrt{\frac{\text { Reputation }_{\text {Mediajit }}+1}{2}}+1, \text { actor does not participate }\end{array}\right.$

\section{Payoff matrix}

Table 1 lists categorical values of input parameters and consequent categorical change in group opinion and news outlet reputation for all permutations of a single actor, single target political group, single news outlet, and single discussion topic. Only two of eight combinations change group scores away from the currently held opinion: there are more strategic options for reinforcing rather than changing currently held beliefs. It is also noteworthy that there are no permutations which allow for actors to simultaneously change the category of group opinion and news outlet reputation. This suggests that actors may need to adopt mixed strategies to optimize short term changes in opinion and reputation for long term success after many games.

Table 2 shows a hypothetical simplified payoff matrix for all permutations of simultaneous Actor 1 and Actor 2 strategies if each actor was limited to one conversation topic instead of 5 . Since the utility functions involve multiple equations, the table lists which variables differ from the default utility function in Equation 1. Table 2 is a $4 \times 4$ matrix. When all 5 conversation topics are implemented, the payoff matrix is $36 \times 36$.

\section{Datasets}

Survey-based estimates of 2016 democratic, republican, and independent percent support for climate change regulation, funding for renewable energy projects, belief whether climate change is real, caused by human activity, and harms the U.S. was downloaded for each state from the Yale Center for Climate Change Communication (http://climatecommunication.yale.edu/ about/projects/yale-climate-opinion-maps/). State level estimates were derived from multilevel regression and post-stratification models using county level demographics and 22,000 survey responses. Validation studies found regression model estimates were within 3\% of independent surveys at the state level (Howe et al., 2015).

Estimated percentages of republican, democratic, and independent adults for each state are from the 2014 U.S. Religious Landscape Study performed by the Pew Research Center. Responses were collected from 35,071 telephone interviews. Approximate margin of error for the entire survey is $0.6 \%$. Approximate margin of errors for each state vary by sample size and range from $1.5 \%$ to $7 \%$. See http://www.pewforum.org/ religious-landscape-study/compare/party-affiliation/by/ state for sample sizes and corresponding approximate margin of errors for each state.

\section{Model implementation}

For each state, 25 sequential game models were run using the Yale Change Climate data as starting values for climate change opinion and state-level political party distribution based on Pew Research Group estimates. Media reputations for republican parties were initialized as 0.5 and -0.5 for anti-and positive climate change news outlets, respectively. For democratic parties, media reputations were initialized as -0.5 and 0.5 for anti- and pro climate change news outlets, respectively. For independent parties, all media reputations were initialized as 0.25 .

Game models were run in Python 3.5. Python code and model output are available at https://github.com/ larkinandy/Game-Theory-Climate-Change-Communication.

\section{Data analysis}

Spatial distribution of cumulative payoffs after 25 games were mapped using ArcGIS 10.3.1 Change in payoffs over time for each state and republican and democratic parties were graphed in Excel 2016. Distribution of strategies for the five states with the highest percent democratic and percent republican base were stratified by pro and anti-climate change news outlets and graphed in Excel 2016.

\section{RESULTS}

\section{Temporal change in public opinion}

Figure 2 shows change in Democratic and Republican opinion in Montana and Hawaii (states with a majority republican and democratic population, respectively) across 25 sequential games. Opinions after each game are shown for each strategy topic. From games 0 to 9 opinions for both democrats and republicans became increasingly partisan. Support for renewable energy and belief in climate change was greater in general than support for regulation and belief that climate change is harmful and manmade among both democrats and republicans. Most notably, at weeks 9 and 10 republican support for renewable energies diverges from other topic opinions. Democratic opinion in Montana takes longer to converge than Hawaii. Similarly, republican opinion in Hawaii (except for renewable energy) takes longer to converge than Montana. 
Table 1. Parameter space of model components transformed to categorical variables.

\begin{tabular}{llllll}
\hline Opinion $_{\text {Actor }}$ & Opinion $_{\text {Groupi }}$ & Reputation $_{\text {Mediaji }}$ & $\boldsymbol{\Delta O p i n i o n}_{\text {Groupi }}$ & $\boldsymbol{\Delta R e p u t a t i o n}_{\text {Mediaji }^{*}}$ & Reputation $_{\text {Mediaji }^{* *}}$ \\
\hline Deny & Deny & Non- Reputable & More Deny & Increased Rep & Decreased Rep \\
Deny & Deny & Reputable & More Deny & Increased Rep & Decreased Rep \\
Deny & Believe & Non- Reputable & More Believe & None & None \\
Deny & Believe & Reputable & More Deny & None & None \\
Believe & Deny & Non- Reputable & More Deny & None & None \\
Believe & Deny & Reputable & More Believe & None & None \\
Believe & Believe & Non- Reputable & More Believe & Increased Rep & Decreased Rep \\
Believe & Believe & Reputable & More Believe & Increased Rep & Decreased Rep \\
\hline
\end{tabular}

Change in opinion attributed to the echo chamber are shown in blue, whereas changes in opinion associated with the boomerang effect are shown in red. Changes which reinforce the echo chamber are shown in green, whereas changes which attenuate the echo chamber effect are shown in purple. Change in opinion that diverges from current group opinion are highlighted in bold. * Actor chooses to participate with news outlet; ${ }^{* *}$ Actor chooses not to participate with news outlet.

Table 2. Utility functions for all permutations of simultaneous Actor 1 and Actor 2 actions.

\begin{tabular}{|c|c|c|c|c|}
\hline & Actor 1 & & & \\
\hline Actor 2 & Pro-climate Media & Anti-climate Media & Neither & Both \\
\hline $\begin{array}{l}\text { Pro-climate } \\
\text { media }\end{array}$ & $I_{\text {MediaAnti }}=0$ for Actors 1 and 2 & $\begin{array}{l}I_{\text {MediaPro }}=0 \text { for Actor } 1 \\
I_{\text {MediaAnti }}=0 \text { for Actor2 }\end{array}$ & $\begin{array}{l}\mathrm{I}_{\text {Actor }}=0 \text { for Actor } 1 \\
\mathrm{I}_{\text {MediaAnti }}=0 \text { for Actor2 }\end{array}$ & $I_{\text {MediaAnti }}=0$ for Actor2 \\
\hline $\begin{array}{l}\text { Anti-climate } \\
\text { media }\end{array}$ & $\begin{array}{l}\mathrm{IMediaAnti}=0 \text { for Actor } 1 \\
\mathrm{I}_{\text {MediaPro }}=0 \text { for Actor2 }\end{array}$ & $I_{\text {MediaPro }}=0$ for Actors 1 and 2 & $\begin{array}{l}\mathrm{I}_{\text {Actor }}=0 \text { for Actor } 1 \\
\mathrm{I}_{\text {MediaPro }}=0 \text { for Actor2 }\end{array}$ & $I_{\text {MediaPro }}=0$ for Actor2 \\
\hline Neither & $\begin{array}{l}\mathrm{I}_{\text {MediaAnti }}=0 \text { for Actor } 1 \\
\mathrm{I}_{\text {Actor }}=0 \text { for Actor2 }\end{array}$ & $\begin{array}{l}\mathrm{I}_{\text {MediaPro }}=0 \text { for Actor } 1 \\
\mathrm{I}_{\text {Actor }}=0 \text { for Actor2 }\end{array}$ & 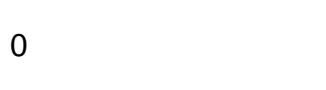 & $\mathrm{I}_{\text {Actor }}=0$ for Actor2 \\
\hline Both & $I_{\text {MediaAnti }}=0$ for Actor 1 & $I_{\text {MediaPro }}=0$ for Actor 1 & $I_{\text {Actor }}=0$ for Actor 1 & Full Model \\
\hline
\end{tabular}

\section{Spatial change in public opinion}

Spatial distribution of change in support for renewable energy is shown below in Figure 3. Support increased among Democrats in all states except for Mississippi. Support among Republicans increased in 42 out of 50 states. Modeled republican support for renewable energies decreased in Arkansas, Idaho, Indiana, Kansas, Louisiana, Michigan, Missouri, and Texas. These states are noteworthy as they defy national trends and further exacerbate differences between political groups.

\section{Actor strategies}

Figure 4 shows the average percent strategy choices for each actor and news outlet type for the top 5 republican and democratic states (Individual state results are available in Supplemental Table 1). For the pro climate change actor, the dominant strategy in 52 to $82 \%$ of games consisted of renewable energy discussions with both pro and anti-climate change news outlets. When engaging with anti-climate change outlets, pro cc actors used a mixed strategy of discussing renewable energy, whether climate change is caused by humans $(29 \%)$, and other discussion topics to a lesser extent.
Strategies for the anti-climate change actor are more mixed. When engaging with pro climate change news outlets, the anti-climate change actor adopted a mixed strategy of all topics, although renewable energies were discussed to a lesser extent. Notably, the anti-climate change actor chose to discuss whether climate change is happening 28 to $32 \%$ of the time with pro climate change news outlets. For anti-climate change news outlets, the anti-climate change actor adopted a mixed strategy with a high probability of refuting that climate change is caused by humans and, to a lesser extent, that climate change harms the US and should be regulated.

Grouped analysis in Figure 4 shows that for both pro and climate change actors, modeled strategies were similar across states with different majority political parties but differed between news outlet type. This is in partially in agreement with Figure 2, which shows similarity across state types as well.

\section{DISCUSSION}

\section{Comparison between states}

Modeled change in opinion over time in Figures 2 suggests that, except for renewable energies, media and 


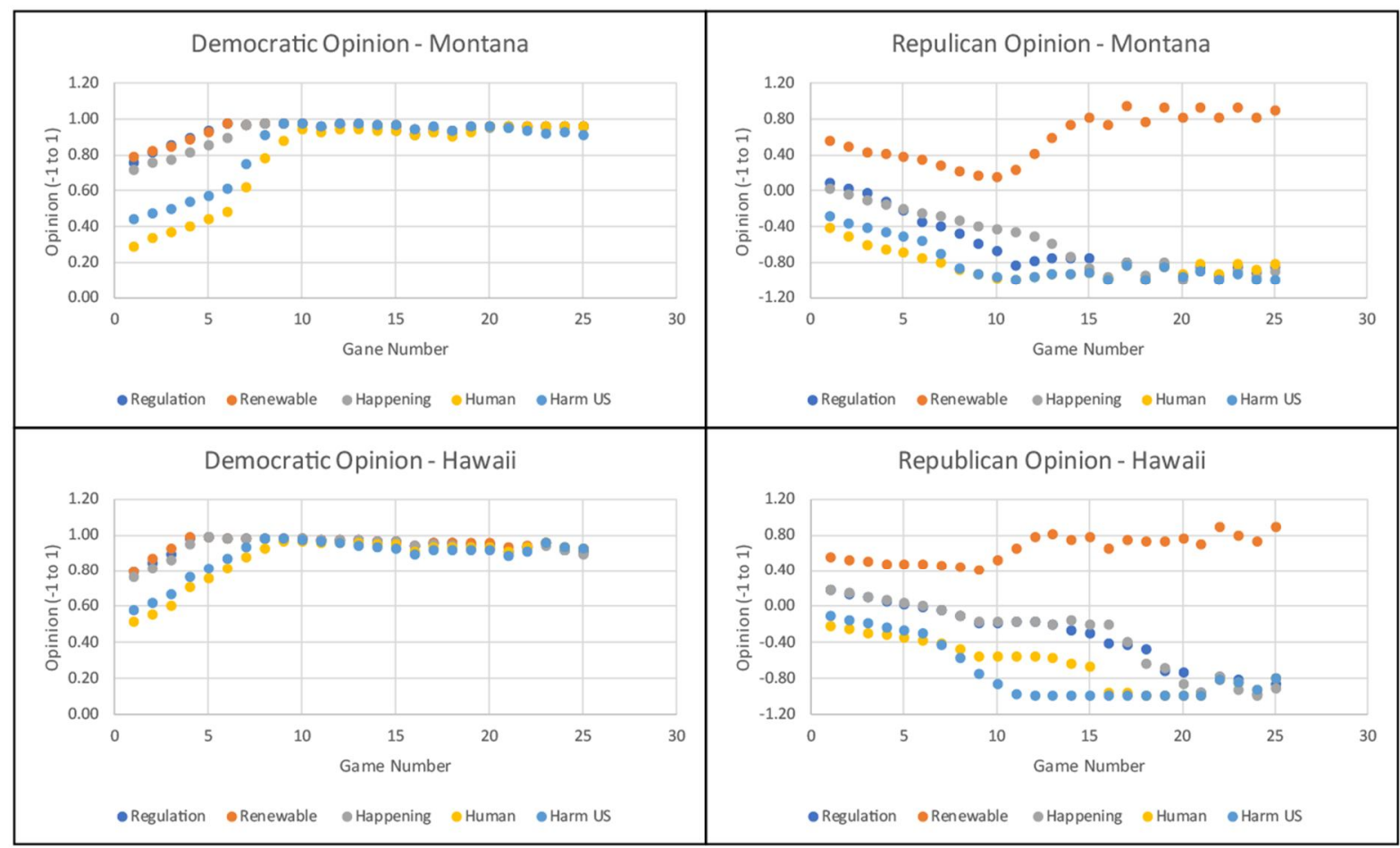

Figure 2. Game theory model change in opinion for climate change-related measures among democrats (left) and republicans (right) in Montana (top) and Hawaii (bottom) across 25 sequential games. Opinion scores range from -1 to 1 , where -1 is completely for and against, respectively climate change regulation and belief. While the model suggests whether climate change is man-made, harmful, or should be regulated is highly partisan, there's bipartisan support for funding renewable energy projects.

\section{Predicted Change in Support for Funding Renewable Energy Projects}

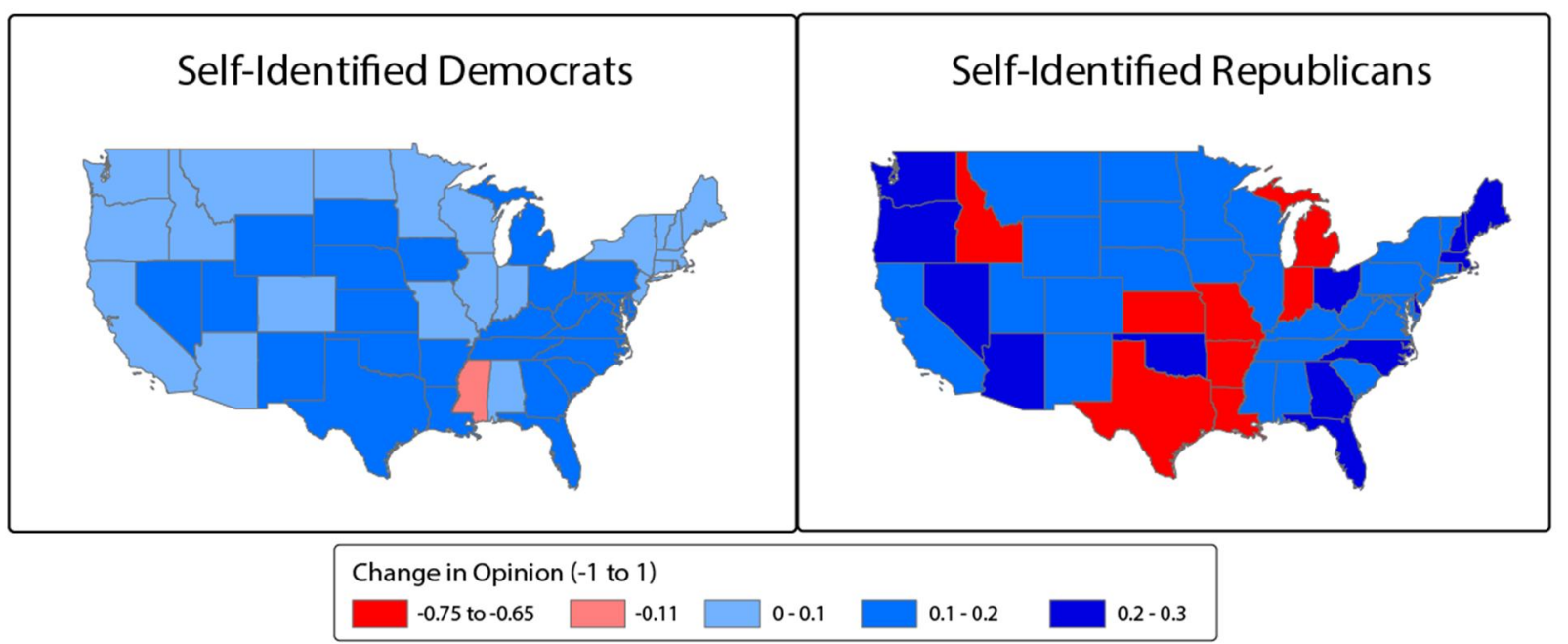

Figure 3. Spatial distribution of change in support for renewable energy over 25 games.

actor influences on climate change opinions are more related to political party than state. However, actor impacts and consequent rates of change varied by state, with democrats in conservative states slower to reach convergence and vice versa, suggesting states with less base support for an actor's view requires more actor 


\section{Pro CC Actor Anti CC Actor}

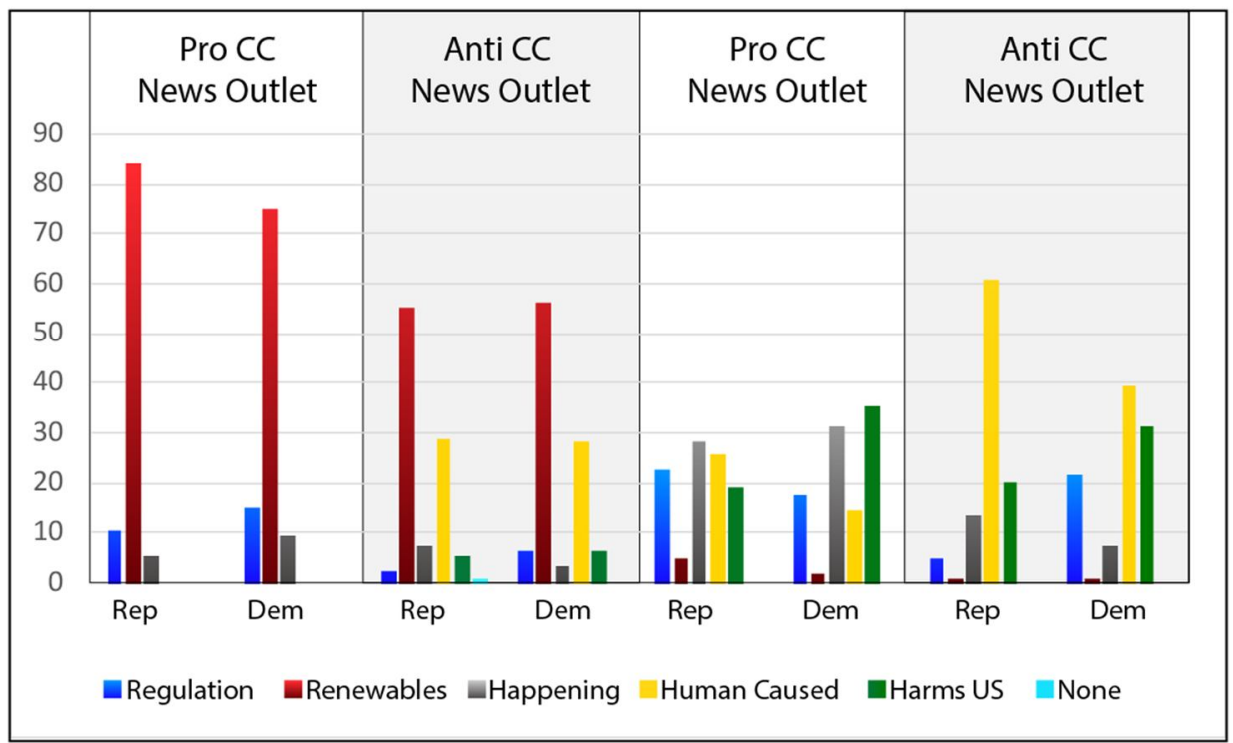

Figure 4. Percent strategy choices across 25 sequential games for pro and anti-climate change actors in the top 5 democratic and republican states, stratified by news outlet type and dominant political party of the state.

actions to reach sustainable climate change opinion levels than states with a strong base support, even within the supporting party.

Figures 2 and 3 suggest climate change scientists can engage republicans and establish bipartisan support in renewable energies. However, while climate change communication strategies don't have to be limited to specific states, communications in select states such as Texas should be carefully considered, as these states defy national trends and communication efforts may further exacerbate partisan differences.

\section{Ideal actor strategies}

Actor strategies in Figure 4 suggest significantly different mixed strategies for pro and anti-climate actors. Pro climate change actors should focus on renewable energies overall and use a mixed strategy including whether humans cause climate change when engaging with anti-climate change news outlets. Similarities between republican and democrat states further support previous inferences suggesting strategies should overall be based on political party and then optimized for each state.

For both actors in the model, engaging with pro and anti-climate change outlets is always a better choice than engaging with one type or no outlets. With the echo chamber effect, any cooperation with a news media and consequent exposure to the support party improves the likelihood of a desired payoff.

\section{Bipartisanship influences in actor decisions}

Contrary to author intuition, model results suggest proand anti-climate change actors receive the best shortterm payoff when strategy choices emphasize reinforcing opinions in the supportive political group rather than changing opinion opposite political party. Actors are penalized when choosing strategies that favor bipartisan communication, and with each successive game republican and democrat parties became increasingly partisan. Pro climate change actors can focus on renewable energies to boost support and potential find an inroad towards more open communications between pro climate change actors and republicans. However, for outcomes such as whether climate change is caused by humans an external factor not included in model parameters may be needed to disrupt what are otherwise dominant, partisan strategies.

\section{Model limitations}

While the developed model was derived from previous research and initialized with empirical observations, the small number of model parameters and simplified equation distributions are too limited for generating real world predictions. Several limitations of the current model include:

1. Implicit assumption of news media outlet cooperation. Future models should include news media outlets as 
actors

2. Small number of potential topics (e.g. extreme weather, research not included in list)

3. Independent voters are included in utility function calculations but ignored in the analysis.

4. Lack of distinguishing between actor types (e.g. politician vs. lobbyist vs. academic, etc.).

5. Lack of disruptive informal news outlets including social media

6. Each game consists of one move from the pro and climate change actor. Future models should include multiple moves within a single game to allow actors to consider longer term payoffs in their utility functions.

7. Finally, the developed game theory model is aggregated to political party groups at the state level and does not adjust for individual socioeconomic characteristics such as income and education which are also strongly associated with climate change opinions (Howe et al., 2015). While useful for developing strategies to target large groups, this model is susceptible to ecological fallacy, where climate change opinions and concomitant optimal communication strategies may differ for subgroups and individuals within each political party. For example, previously in this manuscript we highlighted the divergence between predicted support for renewable energies between self-identified republicans overall and those in Texas. This may be partly attributable to the large role oil production plays in the Texas economy, and dependence of many republican Texans on the oil industry for income.

\section{Actor heterogeneity}

As described in the limitations, optimal communication strategies for a large political party group may differ from ideal strategies for subgroups and individuals. Intra party heterogeneity may not only drive insights into important socioeconomic characteristics that influence climate change opinions, but also identify potential subgroups receptive to specific climate change messages. If climate change opinions continue to become more partisan, these subgroups may be key to brokering long term climate change cooperation strategies which are tolerable, if not amenable, to an overall majority of the population, if not a majority within each political party.

\section{CONCLUSIONS}

Climate change perceptions and media coverage in the United States have become increasingly partisan. In the developed game theory model, dominant strategies for both pro- and anti- climate change further exacerbate partisanship and divergence of perceptions between democrats and republicans. Pro climate change actors can focus on renewable energies to attenuate some of the divide between democratic and republican opinions. However, model predictions suggest, an external disruptive factor is necessary to disrupt the payoff or utility functions and promote a Nash equilibrium (equilibrium where neither actor will likely benefit from disrupting the balance) with less difference in opinion between democrat and republican parties.

\section{REFERENCES}

Bliuc, A. M., McGarty, C., Thomas, E. F., Lala, G., Berndsen, M. and Misajon, R. (2015). Public division about climate change rooted in conflicting socio-political identities. Nature Climate Change, 5(3): 226.

Carmichael, J. T., Brulle, R. J. and Huxster, J. K. (2017). The great divide: understanding the role of media and other drivers of the partisan divide in public concern over climate change in the USA, 2001-2014. Climatic Change, 141(4): 599-612.

Chan-OImsted, S., Rim, H., and Zerba, A. (2013). Mobile news adoption among young adults: Examining the roles of perceptions, news consumption, and media usage. Journalism and Mass Communication Quarterly, 90(1): 126-147.

Howe, P. D., Mildenberger, M., Marlon, J. R., and Anthony Leiserowitz, A. (2015). Geographic variation in opinions on climate change at state and local scales in the USA. Nature Climate Change volume 5, 596-603.

Hicks, D. J. (2017). Scientific controversies as proxy politics. Issues in Science and Technology, 33(2): 67.

Lee, T. M., Markowitz, E. M., Howe, P. D., Ko, C. Y. and Leiserowitz, A. A. (2015). Predictors of public climate change awareness and risk perception around the world. Nature Climate Change, 5(11): 10141020.

Metzger, M. J., Hartsell, E. H. and Flanagin, A. J. (2015). Cognitive dissonance or credibility? A comparison of two theoretical explanations for selective exposure to partisan news. Communication Research, 0093650215613136.

Mildenberger, M., Marlon, J. R., Howe, P. D. and Leiserowitz, A. (2017). The spatial distribution of Republican and Democratic climate opinions at state and local scales. Climatic Change, 145(3-4): 539548.

Nordhaus, W. D. and Yang, Z. (1996). A regional dynamic generalequilibrium model of alternative climate-change strategies. The American Economic Review, 86(4): 741-765.

Perrin, A. (2015). Social media usage. Pew Research Center. Retrieved from http://www.gbcinteractive.com/s/PI_2015-1008 Social-Networking-Usage-2005-2015 FINAL.pdf.

Shapiro, J. M. (2016). Special interests and the media: Theory and an application to climate change. Journal of Public Economics, 144: 91108.

Shin, D., Song, J. H. and Biswas, A. (2014). Electronic word-of-mouth (eWOM) generation in new media platforms: The role of regulatory focus and collective dissonance. Marketing Letters, 25(2): 153-165.

Tingley, D. and Tomz, M. (2014). Conditional cooperation and climate change. Comparative Political Studies, 47(3): 344-368.
Citation: Larkin, A. (2019). Developing climate change communication strategies with game theory. Net Journal of Social Sciences, 7(1): 15-27. 


\section{SUPPLEMENTAL MATERIALS}

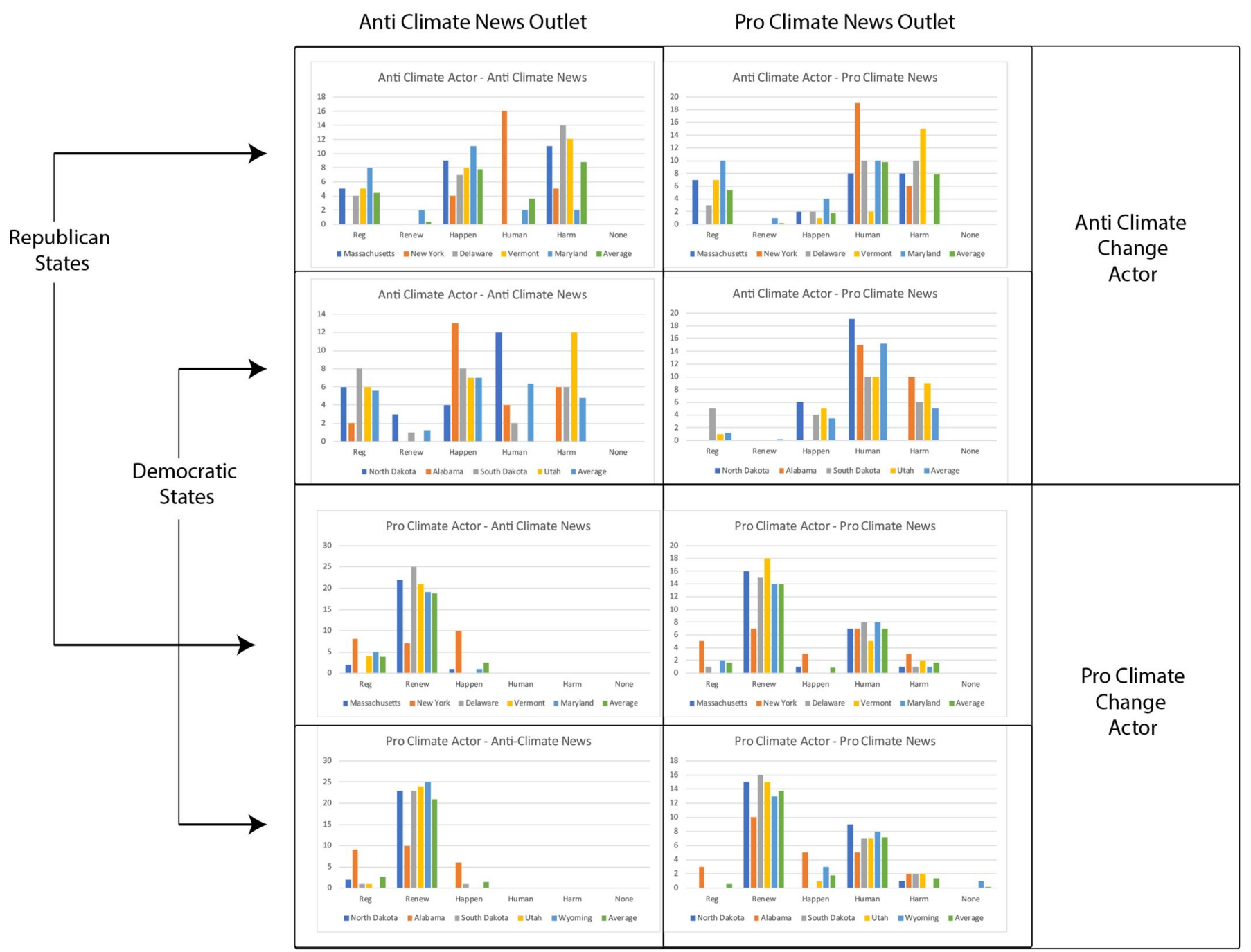

Supplemental Figure 1. Pro- and anti-climate change actor strategy frequencies across 25 sequential games for the top 5 republican and democrat states, for pro and anti-climate change news outlets. 
Supplemental Table 1. Change in republican opinion from baseline after 25 games.

\begin{tabular}{|c|c|c|c|c|c|}
\hline State & Regulation & Renewables & Happening & Human & HarmUS \\
\hline Kansas & -1.09 & -1.43 & -0.96 & -0.58 & -0.67 \\
\hline Louisiana & -1.10 & -1.43 & -0.97 & -0.63 & -0.69 \\
\hline Michigan & -1.13 & -1.41 & -0.99 & -0.65 & -0.71 \\
\hline Missouri & -1.09 & -1.41 & -0.96 & -0.61 & -0.69 \\
\hline Arkansas & -1.12 & -1.40 & -0.96 & -0.60 & -0.66 \\
\hline Idaho & -1.10 & -1.40 & -1.02 & -0.48 & -0.62 \\
\hline Indiana & -1.08 & -1.39 & -0.92 & -0.60 & -0.68 \\
\hline Texas & -1.03 & -1.31 & -0.99 & -0.58 & -0.71 \\
\hline New York & 0.31 & 0.13 & 0.16 & -0.69 & -0.76 \\
\hline Alabama & 0.49 & 0.17 & 0.43 & -0.51 & -0.42 \\
\hline Wyoming & -0.79 & 0.21 & -0.79 & -0.45 & -0.79 \\
\hline North Dakota & -0.91 & 0.22 & -0.74 & -0.42 & -0.67 \\
\hline Illinois & 0.53 & 0.23 & 0.54 & -0.41 & -0.27 \\
\hline Alaska & -1.17 & 0.25 & -1.14 & -0.58 & -0.70 \\
\hline Virginia & -1.06 & 0.27 & -0.96 & -0.64 & -0.57 \\
\hline Nebraska & -0.95 & 0.27 & -0.85 & -0.40 & -0.70 \\
\hline lowa & -0.91 & 0.28 & -0.94 & -0.57 & -0.78 \\
\hline Wisconsin & -1.00 & 0.32 & -0.89 & -0.46 & -0.71 \\
\hline Tennessee & -1.07 & 0.32 & -0.91 & -0.58 & -0.69 \\
\hline Montana & -0.92 & 0.32 & -0.91 & -0.40 & -0.70 \\
\hline New Jersey & -1.17 & 0.33 & -0.95 & -0.53 & -0.60 \\
\hline Hawaii & -1.05 & 0.33 & -1.10 & -0.59 & -0.70 \\
\hline South Carolina & -1.10 & 0.35 & -0.93 & -0.55 & -0.63 \\
\hline Kentucky & -1.07 & 0.35 & -0.90 & -0.53 & -0.60 \\
\hline Utah & -0.99 & 0.35 & -0.88 & -0.47 & -0.49 \\
\hline Vermont & -1.12 & 0.35 & -0.87 & -0.61 & -0.56 \\
\hline Minnesota & -1.06 & 0.37 & -0.92 & -0.58 & -0.70 \\
\hline Pennsylvania & -1.14 & 0.37 & -0.91 & -0.63 & -0.58 \\
\hline New Mexico & -0.95 & 0.37 & -0.92 & -0.56 & -0.74 \\
\hline California & -1.15 & 0.37 & -1.06 & -0.59 & -0.77 \\
\hline Mississippi & 0.57 & 0.37 & -0.22 & -0.62 & -0.52 \\
\hline South Dakota & -1.01 & 0.38 & -0.96 & -0.53 & -0.57 \\
\hline Maryland & -1.10 & 0.38 & -0.96 & -0.57 & -0.66 \\
\hline West Virginia & -0.95 & 0.38 & -0.76 & -0.51 & -0.57 \\
\hline Colorado & -0.94 & 0.38 & -0.86 & -0.42 & -0.55 \\
\hline Connecticut & -1.04 & 0.39 & -0.93 & -0.49 & -0.57 \\
\hline Massachusetts & -1.15 & 0.40 & -0.92 & -0.58 & -0.57 \\
\hline Nevada & -0.94 & 0.41 & -0.91 & -0.45 & -0.76 \\
\hline Georgia & -0.34 & 0.41 & -0.17 & -0.43 & -0.26 \\
\hline Delaware & -1.14 & 0.41 & -0.86 & -0.61 & -0.56 \\
\hline Florida & -1.11 & 0.41 & -0.84 & -0.50 & -0.55 \\
\hline Arizona & -0.99 & 0.42 & -0.88 & -0.47 & -0.55 \\
\hline Maine & -1.10 & 0.42 & -0.94 & -0.53 & -0.59 \\
\hline Washington & -0.96 & 0.45 & -0.93 & -0.40 & -0.71 \\
\hline New Hampshire & -0.92 & 0.46 & -0.79 & -0.39 & -0.67 \\
\hline North Carolina & -1.05 & 0.47 & -0.88 & -0.51 & -0.50 \\
\hline Ohio & -0.92 & 0.47 & -0.80 & -0.40 & -0.67 \\
\hline Oregon & -1.06 & 0.48 & -0.91 & -0.38 & -0.60 \\
\hline Oklahoma & -1.04 & 0.49 & -0.84 & -0.46 & -0.61 \\
\hline Rhode Island & -0.97 & 0.50 & -0.83 & -0.52 & -0.52 \\
\hline
\end{tabular}


Supplemental Table 2. Change in democratic opinion from baseline after 25 games.

\begin{tabular}{|c|c|c|c|c|c|}
\hline State & Regulations & Renewables & Happening & Human & Harm \\
\hline Alabama & 0.15 & 0.07 & 0.37 & -0.07 & 0.27 \\
\hline Alaska & 0.18 & 0.19 & 0.20 & 0.73 & 0.45 \\
\hline Arizona & 0.22 & 0.19 & 0.23 & 0.57 & 0.44 \\
\hline Arkansas & 0.32 & 0.22 & 0.40 & 0.74 & 0.57 \\
\hline California & 0.22 & 0.18 & 0.21 & 0.54 & 0.38 \\
\hline Colorado & 0.20 & 0.18 & 0.21 & 0.58 & 0.44 \\
\hline Connecticut & 0.21 & 0.19 & 0.27 & 0.54 & 0.44 \\
\hline Delaware & 0.30 & 0.21 & 0.27 & 0.55 & 0.52 \\
\hline Florida & 0.32 & 0.22 & 0.29 & 0.60 & 0.51 \\
\hline Georgia & 0.39 & 0.27 & 0.40 & 0.81 & 0.64 \\
\hline Hawaii & 0.12 & 0.13 & 0.13 & 0.42 & 0.35 \\
\hline Idaho & 0.20 & 0.18 & 0.23 & 0.77 & 0.40 \\
\hline Illinois & 0.22 & 0.19 & 0.30 & 0.62 & 0.55 \\
\hline Indiana & 0.30 & 0.19 & 0.37 & 0.75 & 0.63 \\
\hline lowa & 0.21 & 0.21 & 0.32 & 0.60 & 0.51 \\
\hline Kansas & 0.25 & 0.21 & 0.32 & 0.72 & 0.52 \\
\hline Kentucky & 0.31 & 0.22 & 0.44 & 0.69 & 0.61 \\
\hline Louisiana & 0.34 & 0.29 & 0.44 & 0.77 & 0.64 \\
\hline Maine & 0.23 & 0.14 & 0.29 & 0.51 & 0.46 \\
\hline Maryland & 0.29 & 0.21 & 0.26 & 0.59 & 0.50 \\
\hline Massachusetts & 0.23 & 0.15 & 0.26 & 0.50 & 0.42 \\
\hline Michigan & 0.26 & 0.21 & 0.38 & 0.72 & 0.60 \\
\hline Minnesota & 0.20 & 0.17 & 0.28 & 0.55 & 0.51 \\
\hline Mississippi & 0.10 & -0.22 & -0.30 & -1.04 & -0.34 \\
\hline Missouri & 0.29 & 0.20 & 0.34 & 0.68 & 0.56 \\
\hline Montana & 0.20 & 0.17 & 0.24 & 0.67 & 0.47 \\
\hline Nebraska & 0.23 & 0.22 & 0.32 & 0.71 & 0.48 \\
\hline Nevada & 0.19 & 0.20 & 0.25 & 0.58 & 0.41 \\
\hline New Hampshire & 0.22 & 0.16 & 0.31 & 0.56 & 0.40 \\
\hline New Jersey & 0.20 & 0.18 & 0.26 & 0.61 & 0.44 \\
\hline New Mexico & 0.22 & 0.22 & 0.30 & 0.54 & 0.51 \\
\hline New York & 0.24 & 0.13 & 0.20 & 0.51 & 0.36 \\
\hline North Carolina & 0.32 & 0.27 & 0.32 & 0.70 & 0.56 \\
\hline North Dakota & 0.21 & 0.16 & 0.29 & 0.67 & 0.54 \\
\hline Ohio & 0.31 & 0.21 & 0.36 & 0.61 & 0.51 \\
\hline Oklahoma & 0.25 & 0.22 & 0.38 & 0.72 & 0.55 \\
\hline Oregon & 0.18 & 0.12 & 0.16 & 0.53 & 0.36 \\
\hline Pennsylvania & 0.22 & 0.21 & 0.30 & 0.63 & 0.51 \\
\hline Rhode Island & 0.27 & 0.16 & 0.28 & 0.43 & 0.43 \\
\hline South Carolina & 0.32 & 0.26 & 0.37 & 0.88 & 0.65 \\
\hline South Dakota & 0.19 & 0.21 & 0.26 & 0.69 & 0.51 \\
\hline Tennessee & 0.25 & 0.24 & 0.46 & 0.72 & 0.54 \\
\hline Texas & 0.32 & 0.23 & 0.34 & 0.66 & 0.49 \\
\hline Utah & 0.21 & 0.21 & 0.24 & 0.72 & 0.49 \\
\hline Vermont & 0.17 & 0.16 & 0.27 & 0.48 & 0.47 \\
\hline Virginia & 0.25 & 0.22 & 0.25 & 0.63 & 0.53 \\
\hline Washington & 0.20 & 0.18 & 0.22 & 0.53 & 0.35 \\
\hline West Virginia & 0.23 & 0.23 & 0.38 & 0.72 & 0.70 \\
\hline Wisconsin & 0.21 & 0.18 & 0.30 & 0.62 & 0.48 \\
\hline Wyoming & 0.13 & 0.22 & 0.33 & 0.72 & 0.51 \\
\hline
\end{tabular}

